\title{
Pendampingan Pemilihan Jajanan Halālan Tayyiban bagi Kesehatan Anak Sekolah Dasar di SD Muhammadiyah 01 Wuled
}

\author{
Assistance in the Selection of Halālan Tayyiban Snacks for the Health of Elementary School \\ Children at SD Muhammadiyah 01 Wuled
}

Risdiani $^{\mathbf{1}^{*}}$
Yuni Sandra Pratiwi ${ }^{1}$
Warsiyah ${ }^{2}$
1Department of Physical Education,
Universitas Muhammadiyah
Pekajangan Pekalongan,
Pekalongan, Central Java, Indonesia
2Faculty of Islamic Religion,
Universitas Islam Sultan Agung,
Semarang, Central Java, Indonesia
email: risdiani08@gmail.com
Kata Kunci
Halälan Tayyiban
Jajanan
Kesehatan Anak
Keywords:
Halälan Tayyiban
Snacks
Child health
Published: January 2022

\begin{abstract}
Abstrak
Kegiatan pengabdian kepada masyarakat ini bertujuan untuk memberikan pengetahuan kepada siswa tentang pemahaman dan pentingnya memilih makanan jajanan halälan tayyiban untuk meningkatkan imunitas anak. Kegiatan Pengabdian ini dilaksanakan di Sekolah Dasar Muhammadiyah 01 Wuled, Tirto, Pekalongan. Sebelum dilakukan sosialisasi responden mengisi pretest terlebih dahulu dan setelah sosialisasi mengisi post test. Olah data dilakukan dengan uji Paired Sample t-test. Melalui program ini pengetahuan siswa tentang pentingnya memilih makanan jajanan Halālan Tayyiban untuk meningkatkan imunitas menjadi meningkat.
\end{abstract}

\begin{abstract}
This community service activity aims to teach students about understanding and the importance of choosing halallan tayyiban snack foods to increase child immunity. This dedication activity was held at this service activity held at Muhammadiyah Elementary School 01 Wuled, Tirto, Pekalongan. Before the socialization of respondents filled the pretest first, and after the socialization, served the post-test when data was done by testing the t-test paired sample. Students' knowledge about the importance of choosing food snacks for the thesis increases immunity through this program.
\end{abstract} Universitas Muhammadiyah Palangkaraya. This is Open Access article under the CC-BY-SA License (http://creativecommons.org/licenses/by-sa/4.0/). DOI: https://doi.org/10.33084/pengabdianmu.v7i1.2258

\section{PENDAHULUAN}

Makanan jajanan sangatlah melekat pada anak sekolah, hampir di semua lingkungan sekolah dapat dijumpai makanan jajanan, bahkan jajanan ini rutin dikonsumsi sebagian besar anak sekolah khususnya anak sekolah dasar karena harganya terjangkau dan menarik dari segi kemasan. Peranan makanan jajanan sangatlah strategis yaitu sebagai asupan tambahan energi, jika diimbangi dengan mutu dan nilai gizi yang diharapkan (Nurbiyati \& Wibowo, 2014). Namun sayangnya beberapa penelitian membuktikan bahwa sebagian jajanan mengandung boraks, formalin, zat pengawet, zat pewarna, zat pemanis, dan garam tidak beryodium. Hal ini mengakibatkan terjadinya beberapa kasus keracunan karena makanan, salah satu kelompok masyarakat yang sering mengalami masalah akibat keracunan makanan adalah anak sekolah, karena jajanan anak sekolah berisiko terhadap cemaran biologis atau kimiawi yang banyak mengganggu kesehatan (Willian, 2014). Berdasarkan data Kejadian Luar Biasa (KLB) pada jajanan anak sekolah tahun 2004-2006, kelompok siswa sekolah dasar (SD) paling sering mengalami keracunan pangan. Survey Badan Pengawas Obat dan Makanan Republik Indonesia (BPOM 
RI) tahun 2004 menunjukkan bahwa 60\% jajanan sekolah tidak memenuhi standar mutu dan keamanan. Tahun 2007 juga membuktikan bahwa 45\% jajanan sekolah merupakan makanan jajanan yang berbahaya (Badan Pengawas Obat dan Makanan Republik Indonesia, 2013). Tahun 2010, temuan lain data survei KLB terdapat 163 kejadian keracunan pangan, berdasarkan jenis pangannya, sebesar 13,5\% jajanan berkontribusi terhadap kasus keracunan. Kondisi tersebut menunjukkan, adanya risiko kejadian penyakit pada anak usia sekolah dasar terkait dengan jajanan yang dikonsumsinya. Keamanan pangan jajanan anak sekolah (PJAS) masih menjadi permasalahan penting. Berdasar data pangan jajanan anak sekolah yang dilakukan BPOM RI cq Direktorat Inspeksi dan Sertifikasi Pangan bersama 26 Balai Besar/Balai POM di seluruh Indonesia pada tahun 2009 menunjukkan bahwa 45\% PJAS tidak memenuhi syarat karena mengandung bahan kimia berbahaya seperti formalin, boraks, rhodamin, mengandung bahan tambahan pangan (BTP), seperti siklamat dan benzoat melebihi batas aman, serta akibat cemaran mikrobiologi. Sedangkan temuan BPOM RI pada tahun 2006-2010 menunjukkan bahwa sebanyak $48 \%$ jajanan anak di sekolah mengandung bahan kimia yang berbahaya, sedangkan jajanan sekolah mengandung BTP diambil dari sampel 6 kota (Jakarta, Serang, Bandung, Semarang, Yogyakarta dan Surabaya), ditemukan 72,08\% positif mengandung zat berbahaya. Selain itu, sebanyak 47,8\% higiene perorang pedagang tidak baik, $62,5 \%$ memiliki sanitasi tidak baik dari segi peralatan, 30,4\% segi menyajikan makanan tidak baik, dan 47,8\% sarana penjaja tidak baik.

Dampak lain sebagaimana disebutkan oleh Cluss et al. (2014) bahwa ketidakmampuan anak memilih jenis jajanan dapat menyebabkan dampak pada obesitas anak. Sementara itu, penelitian Siahaan dan Simanjuntak (2018) merekomendasikan pentingnya edukasi dalam pemilihan jajanan jajanan bagi anak-anak prasekolah untuk membentuk perilaku mereka dan juga untuk mencegah dampak berbahaya dari mengkonsumsi jajanan tidak sehat sejak dini. Anak sekolah, khususnya sekolah dasar pada hakikatnya belum mengerti cara memilih jajanan sehat, mereka membeli jajanan menurut kesukaan mereka sendiri tanpa memikirkan bahan-bahan yang terkandung didalamnya (Wijayanti \& Mutalazimah, 2018). Permasalahan kebiasaan jajan tidak sehat pada siswa harusnya segera ditangani secara sungguh-sungguh agar dapat terhindar dari berbagai macam penyakit, diantaranya resiko keracunan, gangguan pencernaan, dan status gizi buruk pada anak, yang dapat mempengaruhi kesehatan serta prestasi anak di sekolah (Suci, 2009).

Hal ini seperti yang terjadi di Sekolah Dasar Muhammadiyah 01 Wuled, salah satu sekolah dasar yang terletak di wilayah Kecamatan Tirto, Kabupaten Pekalongan dengan jumlah peserta didik lebih dari 200 orang. Lokasi sekolah yang strategis dan jumlah siswa yang banyak membuka peluang bagi penjual jajan untuk menjajakan dagangannya di pinggir-pinggir sekolah. Terdapat 10 sampai 15 pedagang jajanan berjualan di lingkungan sekolah pada jam istirahat dan menjelang pulang sekolah dengan aneka variasi jenis dan cara pengolahan makanannya. Berdasarkan observasi awal, jenis jajanan dan kebersihan alat dan cara penyajiannya kurang higienis dan tidak bersih, hal ini dapat dilihat dari jajanan yang mengandung pewarna tekstil (mencolok), tekstur terlalu kenyal, penggunaan perasa yang sangat kuat, tidak terdapat label pangan, memakai pemanis buatan, didominasi dengan bahan pengawet, disajikan menggunakan kertas bekas, dan dijajakan ditempat terbuka. Meskipun demikian, anak-anak SD sangat tertarik untuk membeli karena tergoda dengan penampilan jajanan yang menarik dan rasanya yang enak, namun tidak mengetahui kandungan zat yang berbahaya dari jajanan tersebut. Hal ini kemudian menurut penuturan kepala sekolah SD Muhammadiyah 01 Wuled menyebabkan tidak kurang dari 5 sampai 6 peserta didik harus dirawat di rumah sakit akibat mengalami gangguan pencernaan.

Melihat temuan ini sudah seharusnya diambil tindakan dan ditangani secara serius agar peserta didik dapat terhindar dari berbagai penyakit termasuk gangguan pencernaan. Alternatif tindakan yang dapat dilakukan untuk mencegah hal tersebut, dengan mengadakan kegiatan pendampingan tentang cara memilih makanan jajanan yang layak untuk dikonsumsi dan menyehatkan. Sama halnya seperti yang dianjurkan dalam ajaran agama Islam dimana manusia diperintahkan untuk mengkonsumsi makanan yang halal lagi baik atau disebut juga makanan halälan tayyiban (Shihab, 2010). Adapun ayat yang menjelaskan tentang makanan halälan tayyiban terdapat dalam Al-Quran Surat Al-Baqarah ayat 168, Al-Maidah ayat 88, An-Nahl ayat 114, dan Surat Al-Anfal ayat 69 (Departemen Agama Republik Indonesia, 2010). Maka berdasar ayat-ayat tersebut syarat utama diperbolehkannya manusia mengkonsumsi makanan ataupun minuman adalah makanan yang haläl lagi tayyib (Nuraini, 2018). 


\section{METODE}

Kegiatan pendampingan pemilihan makanan jajanan halälan tayyiban dilakukan dengan pemberian edukasi tentang makanan jajanan menyehatkan kepada orang tua dan peserta didik di SD Muhammadiyah 01 Wuled. Kegiatan dilaksanakan oleh dosen dan mahasiswa dari Fakultas Ilmu Kesehatan, Universitas Muhammadiyah Pekajangan Pekalongan dengan melibatkan mitra. Adapun pelaksanaan kegiatan pendampingan dilakukan selama dua bulan yaitu bulan Agustus dan September 2020. Alat dan bahan yang digunakan diantaranya laptop, LCD, lembar angket, materi edukasi dalam bentuk Power Point, dan gambar petunjuk makanan jajanan halälan tayyiban. Metode kegiatan pendampingan melalui 5 tahapan:

1. Wawancara

Tahapan yang pertama dilakukan adalah wawancara kepada pihak sekolah. Hal ini dilakukan untuk mendapatkan informasi permasalahan yang dihadapi mitra, terkait beberapa penyakit yang dialami oleh peserta didik, akibat mengkonsumsi makanan jajanan yang tersedia dilingkungan SD Muhammadiyah 01 Wuled diantaranya gangguan pencernaan.

2. Perijinan dan kesepakatan

Tahapan berikutnya setelah wawancara adalah mengajukan perijinan mengenai maksud dan tujuan kegiatan yang akan dilaksanakan, selanjutnya membuat kesepakatan dengan mitra mengenai jadwal pelaksanaan kegiatan pengabdian.

3. Persiapan

Persiapan dilakukan melalui rapat koordinasi antara pelaksana pengabdian kepada masyarakat yaitu dosen dan mahasiswa dengan pihak sekolah. Hasil rapat dibentuk tim pelaksana. Kemudian menyusun teknis pelaksanaan, dan menjelaskan tugas dari masing-masing anggota tim, seperti menyiapkan alat dan tempat, dokumentasi kegiatan, menyiapkan materi edukasi, membagikan poster kepada peserta didik, membagikan angket untuk mengetahui pemahaman peserta didik dan membagikan makanan jajanan halälan tayyiban.

4. Pelaksanaan Kegiatan

Kegiatan pendampingan diawali dengan pembukaan, selanjutnya diikuti dengan pembagian lembar pre-test kepada orang tua dan peserta didik yang berisi pertanyaan-pertanyaan seputar makanan jajanan halälan tayyiban, guna mengukur pengetahuan dan pemahaman peserta didik tentang makanan jajanan halälan tayyiban. Langkah berikutnya penyampaian materi edukasi meliputi pengertian haläl dan tayyib, ciri-ciri makanan halälan tayyiban, tips memilih makanan halälan tayyiban dan akibat mengkonsumsi makanan yang tidak haläl dan tayyib, serta pemberian contoh makanan yang menyehatkan dan dibutuhkan oleh tubuh. Setelah penyampaian materi selesai dilakukan posttest.

5. Evaluasi dan Tindak Lanjut

Evaluasi dilakukan oleh tim pelaksana setelah satu minggu sesudahnya, dan melaporkan hasil kegiatan mitra, untuk kemudian direncanakan kegiatan tindak lanjut.

\section{HASIL DAN PEMBAHASAN}

Kegiatan edukasi pengabdian masyarakat dilaksanakan pada tanggal 18September 2020 diSD Muhammadiyah 01 Wuled dengan pembagian dua sesi, sesi pertama pukul 08.00 sampai 09.00 dan sesi kedua pukul 09.30 sampai 10.30, peserta dalam kegiatan sejumlah 40 yang terdiri dari 20 siswa dan 20 orang tua siswa. Kegiatan diawali dengan acara pembukaan (Gambar 1). Tahap berikutnya pengarahan dari tim pelaksana kepada peserta tentang jalannya kegiatan yang akan dilaksanakan sebelum pemberian materi disampaikan (Gambar 2). 


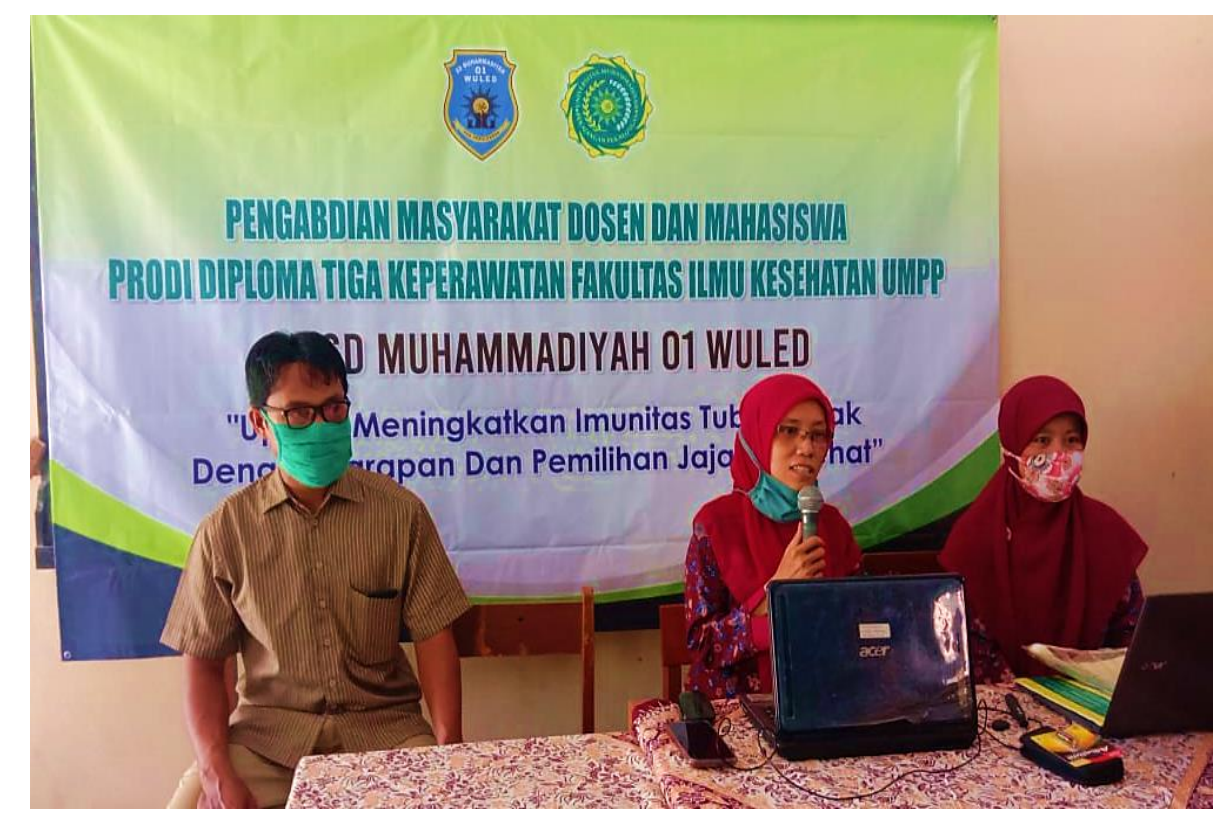

Gambar 1. Acara pembukaan

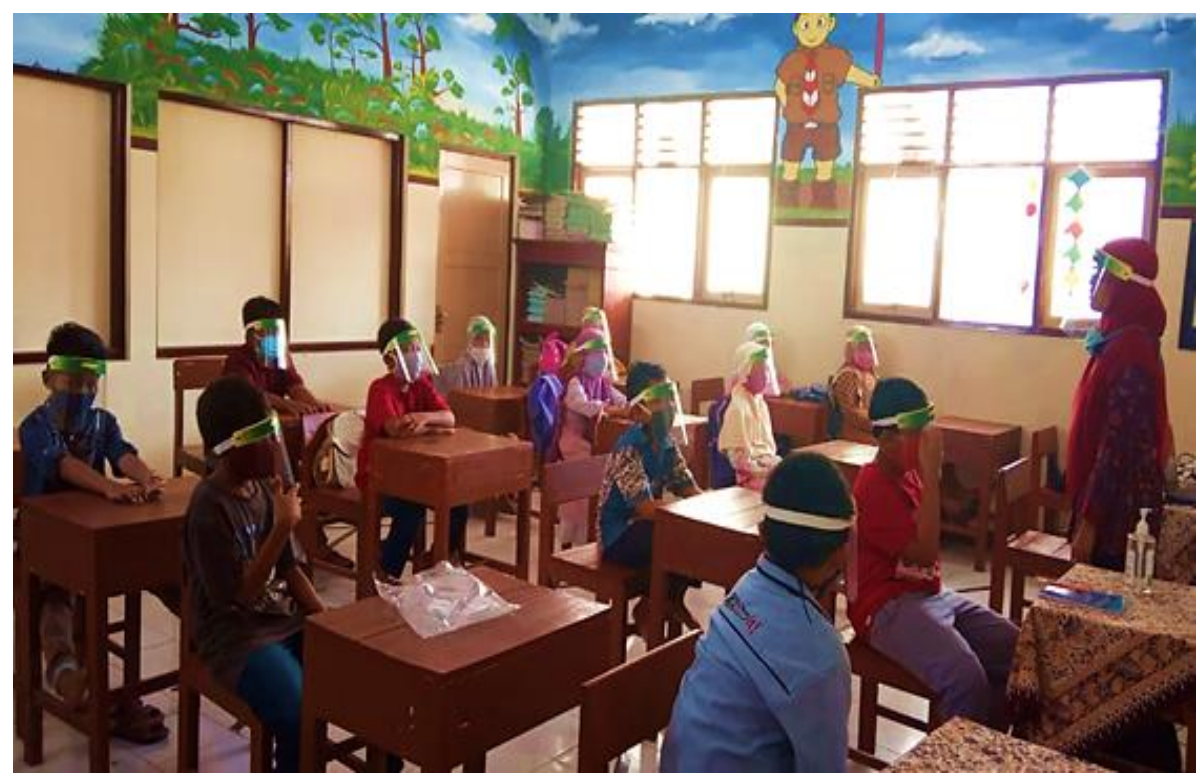

Gambar 2. Pengarahan kepada peserta tentang jalannya kegiatan yang akan dilaksanakan

Sesi selanjutnya membagikan angket pre-test yang berisi pertanyaan-pertanyaan seputar makanan jajanan halälan tayyiban. Setelah angket terkumpul kegiatan berikutnya penyampaian materi edukasi oleh Risdiani dan Yuni Sandra Pratiwi. Materi edukasi yang disampaikan meliputi pengertian haläl dan tayyib, indikator makanan yang halälan tayyiban, dan cara memilih makanan yang halälan tayyiban. Halal artinya setiap sesuatu yang tidak dikenakan sangsi penggunaanya atau sesuatu perbuatan yang dibebaskan syariat untuk dilakukan, sehingga makanan halal adalah makanan yang dibolehkan untuk di konsumsi dan tidak dilarang secara agama (Shihab, 2010). Makanan halal tidak hanya dari segi zatnya namun juga dari segi perolehannya. Sedangkan istilah țayyib dapat diartikan sebagai makanan yang sedap, tidak kotor, dan mengandung nilai gizi dan nutrisi yang dibutuhkan oleh tubuh (Al-Maraghi, 1993). Indikator makanan halälan tayyiban diantaranya diperbolehkan untuk dikonsumsi oleh agama, diperoleh dengan cara yang baik bukan dari mencuri atau riba, sedangkan dari segi zat-nya makanan tidak mengandung bahan-bahan yang berbahaya bagi tubuh dan tercampur dengan sesuatu yang najis misalnya dimasak dengan menggunakan minyak babi, dan makanan yang mengandung gizi yang dikonsumsi sesuai kebutuhan tubuh (Waharjani, 2015). 
Alasan mengapa harus mengkonsumsi makanan yang halälan tayyiban yaitu sebagai tanda kepatuhan kepada Allah SWT, menyehatkan, berpengaruh pada batin, mendapat pahala dan dapat meningkatkan daya tahan tubuh. Adapun Tips memilih makanan halälan tayyiban meliputi tidak dilarang oleh agama untuk dikonsumsi, tidak kotor, tidak tercampur bahan berbahaya, bersih dan aman (Badan Pengawas Obat dan Makanan Republik Indonesia, 2013). Sedangkan akibat mengkonsumsi makanan yang tidak halälan tayyiban yaitu tidak diterimanya do'a dan ibadah seseorang (Nashirun, 2020), jika makanan yang dikonsumsi adalah makanan haram, sedangkan jika makanan yang dikonsumsi tidak tayyib dapat menimbulkan beberapa penyakit misalnya diare, mual muntah, pusing, dan gangguan pencernaan. Penyampaian materi selanjutnya adalah memperlihatkan berbagai contoh gambar makanan halälan tayyiban (Gambar 3), dilanjutkan sesi tanya jawab dan pemberian makananjajanan halālan tayyiban berupa kacang hijau dan aneka olahan dari bahan yang aman untuk dikonsumsi dari olahan rumahan (Gambar 4).

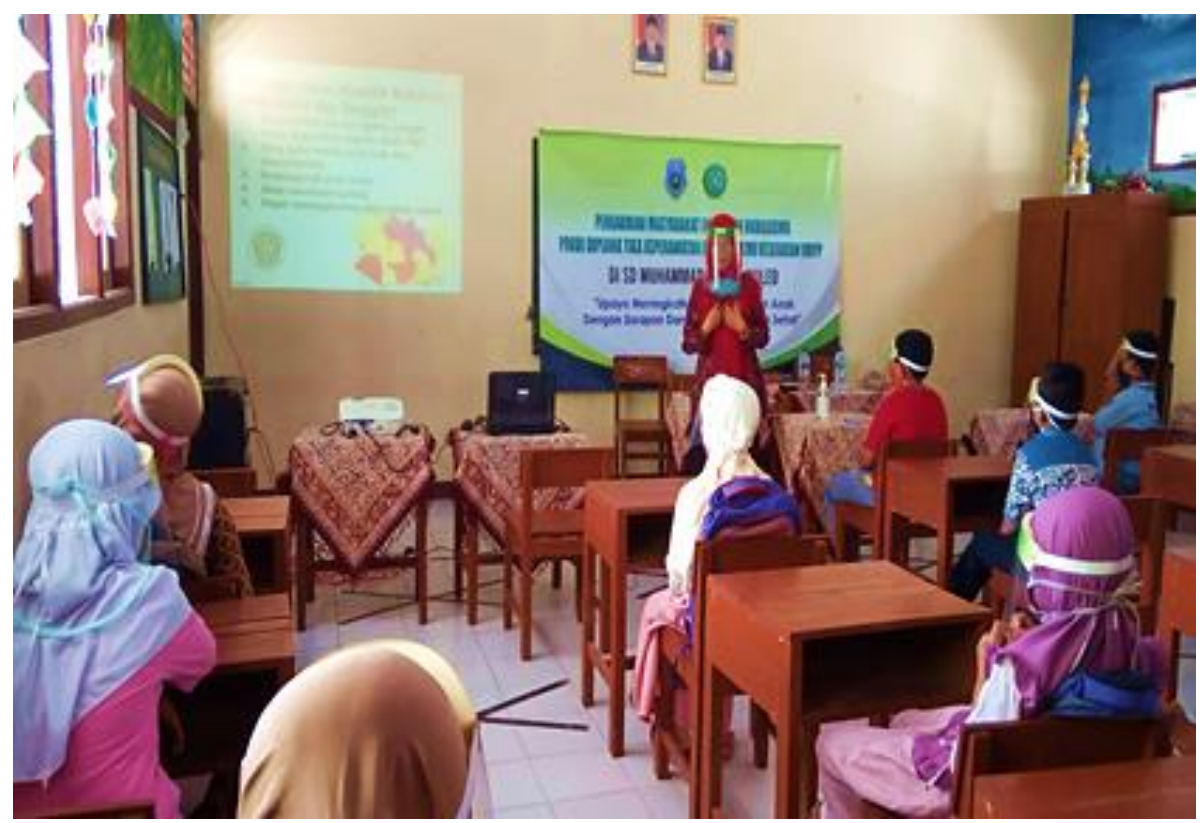

Gambar 3. Kegiatan diskusi dan tanya jawab tentang makanan jajanan halālan tayyiban

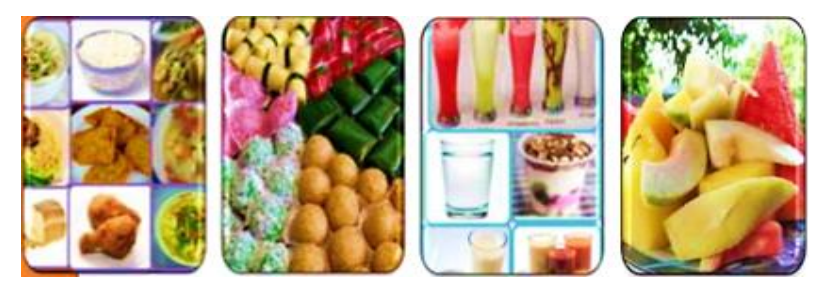

Gambar 4. Gambar berbagai makanan jajanan halālan tayyiban

Kegiatan selanjutnya setelah penyampaian materi dan diskusi dilanjutkan dengan pembagian angket post-test dengan pertanyaan yang sama seperti pada pre-test. Tujuannya untuk mengetahui peningkatan pemahaman peserta didik dan orang tua sesudah pemberian edukasi dilakukan. Kegiatan diakhiri dengan foto bersama (Gambar 5). Setelah kegiatan selesai tim pelaksana melakukan tahap evaluasi kegiatan dan menganalisis hasil pre-test dan post-test. Hasil pre-test kegiatan pengabdian masyarakat pada sejumlah 40 responden dari peserta didapatkan tingkat pengetahuan sedang $60 \%$ dan rendah $40 \%$, sedangkan hasil pada post test tingkat pengetahuan tinggi $62,5 \%$, sedang $27,5 \%$ dan rendah $10 \%$. Hasil ini menunjukkan terdapat pengaruh pemberian edukasi tentang pemilihan makanan jajanan halälan tayyiban dengan nilai p value $0,000<0,05$. Hasil pengabdian masyarakat menunjukkan bahwa terjadi perubahan positif pada peserta pendampingan edukasi tentang makanan jajanan halälan tayyiban yang ditandai dengan meningkatnya pengetahuan orang tua dan peserta didik di SD Muhammadiyah 01 Wuled tentang pemilihan makanan jajanan halälan tayyiban. Akan tetapi, 
perlu adanya upaya berkelanjutan agar edukasi yang telah disampaikan bukan hanya sekedar pengetahuan, namun dapat merubah kebiasaan anak-anak dalam memilih makananjajanan yang menyehatkan untuk dikonsumsi sehari-hari, dengan melibatkan pihak sekolah, orang tua dan para penjual yang berada di sekitar lingkungan sekolah. Hasil tersebut dapat dilihat pada Tabel I sampai III.

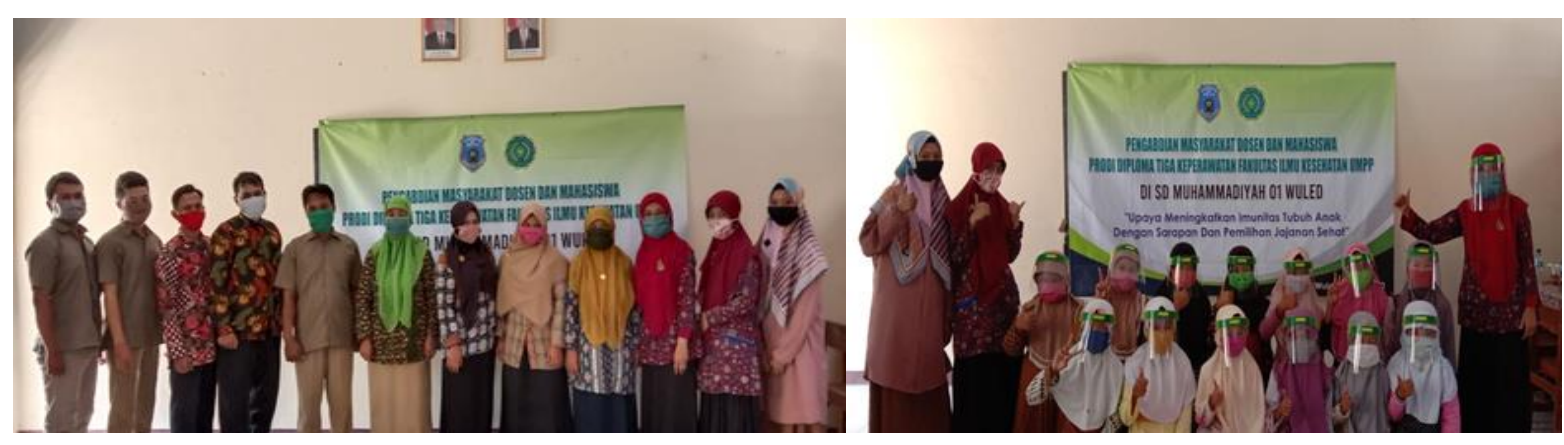

Gambar 5. Foto bersama tim pelaksana dan peserta

Tabel I. Data Pengetahuan Pre-test peserta didik

\begin{tabular}{lccc}
\hline & Pre-test & \\
\hline & Kategori & Frekuensi & 0 \\
\hline Tinggi & 0 & 60 \\
Sedang & 24 & 40 \\
Rendah & 16 & 100 \\
\hline Total & 40 & 0 \\
\hline
\end{tabular}

Tabel II. Data Pengetahuan Post-test peserta didik

\begin{tabular}{lccc}
\hline & Post-test & \\
\hline & Kategori & Frekuensi & \% \\
\hline Tinggi & 25 & 62,5 \\
Sedang & 11 & 27,5 \\
Rendah & 4 & 10 & 100 \\
\hline Total & 40 & \\
\hline
\end{tabular}

Tabel III. Hasil pengaruh sosialisasi pemilihan jajanan halālan tayyiban

\begin{tabular}{lcccc}
\hline & \multicolumn{4}{c}{ Paired samplet-test } \\
\hline & Mean & $\mathbf{t}$ & df & Sig, (2-tailed) \\
\hline Pre-post test & 925 & 12,333 & 39 &, 000 \\
\hline
\end{tabular}

Hasil pengabdian masyarakat ini sejalan dengan hasil penelitian yang dilakukan oleh Kusnul dan Ridwan (2020) mengenai pendidikan kesehatan tentang makanan jajanan di MI Rohmatul Ummah, Klampisan, Kandangan, Kediri. Penelitian tersebut menjelaskan bahwa dengan diadakannya penyuluhan pendidikan kesehatan tentang makanan jajanan terjadi peningkatan pengetahuan anak tentang makanan jajanan yang menyehatkan, namun demikian peningkatan tersebut hanya sebatas level pengetahuan. Oleh karenanya, pendidikan kesehatan tentang makanan jajanan yang menyehatkan memerlukan proses yang panjang sehingga dapat berubah menjadi perilaku dalam keseharian. Sehingga dibutuhkan pendekatan dan tindak lanjut yang komprehensif dengan mengikutsertakan pihak sekolah, orang tua, instansi kesehatan, dan para pedagang makanan jajanan. Begitu juga selaras dengan pengabdian masyarakat yang dilakukan oleh Rahayu Widaryani melalui program sosialisasi pemberian makanan yang bergizi bagi bayi dan anak yang dapat meningkatkan pengetahuan masyarakat tentang pemberian makanan yang baik dan bergizi bagi bayi dan anak (Widaryanti, 2019).

Sama halnya dengan Iklima (2017) dalam penelitiannya tentang gambaran pemilihan makanan jajanan pada anak usia sekolah dasar, menyimpulkan bahwa sebagian besar pemilihan makanan jajanan pada anak usia sekolah dasar lebih cenderung memilih makanan yang tidak baik. sehingga dapat mempengaruhi kesehatan terutama resiko kerusakan organ pencernaan. Untuk mengatasinya, perlu adanya kerjasama antara guru, orang tua dan instansi kesehatan (puskesmas) melalui pendidikan, perhatian dan pengawasan terhadap makanan jajanan pada peserta didik. Sedangkan pengawasan 
dapat dilakukan secara berkala (Hayati \& Nuriya, 2018). Menurut Mavidayanti (2016), upaya lain juga dapat dijadikan alternatif yaitu dengan membuat kebijakan agar peserta didik membawa bekal baik itu sarapan atau makanan jajanan dari rumah serta melarang penjaja makanan jajanan berdagang di depan (lingkungan) sekolah. Hal ini juga harus diimbangi oleh pihak sekolah dengan melengkapi sarana prasarana seperti kantin sehat atau kerjasama katering untuk menyediakan makanan jajanan sehingga bermanfaat bagi kesehatan anak.

\section{KESIMPULAN}

Pengabdian masyarakat yang telah dilakukan dengan pemberian pendampingan tentang pemilihan makanan jajanan yang halālan tayyiban pada anak usia sekolah dasar di SD Muhammadiyah 01 Wuled terbukti berpengaruh terhadap meningkatkan pengetahuan dalam pemilihan makanan jajanan halālan tayyiban dengan nilai p-value $0,000<0,05$. Namun demikian diharapan setelah kegiatan pengabdian masyarakat ini tidak hanya pengetahuan yang meningkat akan tetapi lebih kepada adanya perubahan terhadap kebiasaan peserta didik dalam memilih makanan jajanan halälan tayyiban di sekolah secara berkelanjutan. Untuk itu perlu adanya kerjasama dari semua pihak baik guru, orang tua, penjaja makanan, dan instansi terkait dengan berbagai upaya untuk menunjang program tersebut diantaranya pengawasan, edukasi yang berkelanjutan dan pengadaan kantin sehat atau penyediaan makanan jajanan halālan tayyiban di sekolah.

\section{UCAPAN TERIMA KASIH}

Terimakasih pengabdi ucapkan untuk Universitas Muhammadiyah Pekajangan Pekalongan yang telah memberikan support untuk melakukan kegiatan ini. Selain itu pengabdi juga mengucapkan terimakasih kepada Kepala Sekolah SD Muhammadiyah 01 Wuled Pekalongan yang telah memberikan Ijin dan memberikan kesempatan untuk melaksanakan kegiatan pengabdian.

\section{REFERENSI}

Al-Maraghi, A.M. 1993. Tafsir Al-Maraghi Juz 11. terj. Sitanggal, A.U. (ed.) 2nd ed. Semarang: Karya Toha Putra.

Badan Pengawas Obat dan Makanan Republik Indonesia. 2013. Pedoman Pangan Jajanan Anak Sekolah untuk Pencapaian Gizi Seimbang Bagi Orang Tua, Guru dan Pengelola Kantin. Jakarta: Direktorat Standardisasi Produk Pangan Deputi Bidang Pengawasan Keamanan Pangan dan Bahan Berbahaya, Badan Pengawas Obat dan Makanan Republik Indonesia.

https://standarpangan.pom.go.id/dokumen/pedoman/Buku_Pedoman_PJAS_untuk_Pencapaian_Gizi_Sei mbang_Orang_Tua_Guru_Pengelola_Kantin_pdf

Cluss, P.A., Fee, L., Culyba, R.J., Bhat, K.B., Owen, K. 2014. Effect of food service nutrition improvements on elementary school cafeteria lunch purchase patterns. The Journal of School Health. 84(6):355-362. https://doi.org/10.1111/josh.12157

Departemen Agama Republik Indonesia. 2010. Mushaf al-Qur'an dan Terjemahnya. Jakarta: Pena Pundi Aksara

Hayati, N., Nuriya, H. 2018. Kecenderungan Pemilihan Jajanan pada Anak Usia Sekolah di MI Darul Ulum Kecamatan Ngaliyan Kota Semarang. Jurnal Gizi. 7(1):1-7. https://doi.org/10.26714/jg.7.1.2018.\%25p

Iklima, N. 2017. Gambaran Pemilihan Makanan Jajanan Pada Anak Usia Sekolah Dasar. Jurnal Keperawatan BSI. 5(1):8-17. https://doi.org/10.31311/.v5i1.1774

Kusnul, Z., Ridwan, A. 2020. Pendidikan Kesehatan Tentang Makanan Jajanan di MI Rohmatul Ummah, Klampisan, Kandangan, Kediri. Journal of Community Engagement in Health.3(1):99-103. https://doi.org/10.30994/jceh.v3i1.43 
Mavidayanti, H. 2016. Kebijakan Sekolah dalam Pemilihan Makanan Jajanan pada Anak Sekolah Dasar. JHE (Journal of Health Education). 1(1):71-77

Nashirun. 2020. Makanan Halal dan Haram dalam Persfektif Al Qur'an. Halalan Thayyiban : Jurnal Kajian Manajemen Halal dan Pariwisata Syariah (Journal Of Halal Management, Sharia Tourism and Hospitality Studies). 3(2):1-15

Nuraini. 2018. Halalan Thayyiban Alternatif Qurani untuk Hidup Sehat. Jumal Ilmiah Al-Mu \'ashirah: Media Kajian AlQur \'an dan Al-Hadits Multi Perspektif. 15(1):82-93. http://dx.doi.org/10.22373/jim.v15i1.5460

Nurbiyati, T., Wibowo, A.H. 2014. Pentingnya Memilih Jajanan Sehat Demi Kesehatan Anak. Jurnal Inovasi dan Kewirausahaan : Journal of Innovation and Entrepreneurship. 3(3):192-196

Shihab, M.Q. 2010. Tafsir al-Mishbah: Pesan, Kesan, dan Keserasian al-Qur'an. Volume III. Tangerang: Lentera Hati.

Siahaan, E.R., Simanjuntak, S.M. 2018. The Education of Smart School Snacks towards the Ability of Choosing Snacks at Preschool Children in IKI PTPN VII Way Galih Kindergarten, Tanjung Bintang, Propinsi Lampung. In Proceedings International Scholars Conference. Translating Research in a Borderless Community: From Theory to Action. 6(1):89. https://doi.org/10.35974/isc.v6i1.1386

Suci, E.S.T. 2009. Gambaran Perilaku Jajan Murid Sekolah Dasar di Jakarta. Psikobuana : Jurnal Ilmiah Psikologi. 1(1):29-38

Waharjani. 2015. Makanan Yang Halal Lagi Baik Dan Implikasinya Terhadap Kesalehan Seseorang. Al-Manar : Jurnal Komunikasi dan Pendidikan Islam. 4(2):193-204. https:/ /doi.org/10.36668/jal.v4i2.60

Widaryanti, R. 2019. Cegah Masalah Gizi Anak dengan Sosialisasi Pemberian Makanan Bayi dan Anak. PengabdianMu: Jurnal Ilmiah Pengabdian Kepada Masyarakat. 4(2):94-98. https://doi.org/10.33084/pengabdianmu.v4i2.890

Wijayanti, A.P., Mutalazimah, M. 2018. Hubungan Asupan Energi dengan Status Gizi Anak Autis di Yayasan Pembinaan Anak Cacat (YPAC) Kota Surakarta. Jurnal Kesehatan. 11(1):9-15. https:/ /doi.org/10.23917/jk.v11i1.6999

Willian, N. 2014. Optimalisasi Peran Serta Masyarakat Dalam Peningkatan Kesadaran Peduli Makanan Sehat Tanpa Formalin Pada Jajanan Sekolah. Jurnal Zarah. 2(1):1-11. https://doi.org/10.31629/zarah.v2i1.25 